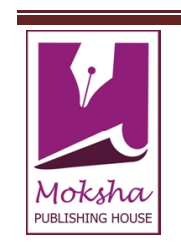

INTERNATIONAL RESEARCH JOURNAL OF PHARMACY

www.irjponline.com

ISSN $2230-8407$

Research Article

\title{
EVALUATION OF- 2, 6-DIMETHYL- N3, N5- DIPHENYL - 1, 4-DIHYDROPYRIDINE - 3,5- DICARBOHYDRAZIDE DERIVATIVES FOR IN VIVO ANTI-INFLAMMATORY AND ANALGESIC ACTIVITIES
}

Asma Samaunnisa A ${ }^{1}$, Riazuddin Mohammed ${ }^{2}$, C.H.S. Venkataramana ${ }^{1}$, V Madhavan ${ }^{3}$

${ }^{1}$ Department of Pharmaceutical chemistry, M. S. Ramaiah College of Pharmacy, Bangalore, India

${ }^{2}$ Department of Medical Biology, Linköping University, Linköping, Sweden

${ }^{3}$ Department of Pharmacognosy, M.S. Ramaiah College of Pharmacy, Bangalore, India

*Corresponding Author Email: asmasamaunnisa@gmail.com

Article Received on: 19/08/13 Revised on: 07/09/13 Approved for publication: 16/09/13

DOI: $10.7897 / 2230-8407.04933$

IRJP is an official publication of Moksha Publishing House. Website: www.mokshaph.com

(C) All rights reserved.

\section{ABSTRACT}

Novel 2,6-dimethyl-N3, N5-diphenyl-1,4-dihydropyridine-3,5-dicarbohydrazide (2A-2D') and its derivatives were synthesized from Diethyl-2,6-dimethyl-1,4dihydropyridine-3,5-dicarboxylates (1A) and Diethyl-4-(4-hydroxyphenyl)-2,6-dimethyl-1,4-dihydropyridine-3,5-dicarboxylates (1A'). A set of 8 new derivatives (2A-2D'), were subjected to in vivo anti-inflammatory and analgesic activities. Anti-inflammatory activity was performed by using Carrageenan induced paw edema method and analgesic activity was performed by Eddy's hot plate method. The obtained results were tabulated and represented graphically using histogram. Activity of all the derivatives was compared with the chosen standards namely indomethacin and tramadol for anti-inflammatory and analgesic activity respectively, using dimethyl sulfoxide (DMSO) as control. Almost all the derivatives of the class exhibited significant activity.

Keywords: In vivo Anti-inflammatory, Analgesic, 1, 4-Dihydropyridine, Dicarbohydrazide.

\section{INTRODUCTION}

Ever since the dawn of mankind there has been an ongoing war between mankind and the diseases. There wasn't a single day that the scientists and researchers stopped looking for better molecules for almost all the existing ailments. One of the most sought after classes of drugs are NSAIDS. Although there are a number of NSAIDS developed and available in market, rigorous search for new molecules is on wheels. This is due to variety of side effects like gastric ulceration, inhibition of platelet function, alteration in renal function, hypersensitivity etc, with the existing molecules. 1, 4dihydropyridine is a 6 membered heterocyclic ring containing nitrogen as hetero atom. This moiety, individually as well as in combination with other moieties is known to possess a variety of pharmacological activities which include antibacterial, antifungal, anti-inflammatory, antihypertensive, anticonvulsant, anticancer, anti-diabetic activities ${ }^{1-10}$. The rationale behind this work is to thoroughly study and investigate the in vivo anti-inflammatory and analgesic activities of 2, 6-dimethyl- $\mathrm{N}^{3}, \quad \mathrm{~N}^{5}$-diphenyl-1, 4dihydropyridine-3, 5-dicarbohydrazide (2A-2D' $)^{13}$. These derivatives might prove to be better leads for the class of NSAIDS, with less side effects and increased therapeutic efficacy.

\section{MATERIALS AND METHODS}

Chemicals and solvents used were of reagent grade and used without further purification, were procured from Spectro Chem, Hi-Media, Merck, Sigma Aldrich and Ranbaxy. The purity of the synthesized compounds was determined by melting point using open capillary method and is uncorrected. IR (infra-red) was performed using SHIMADZU FTIR8400 S. The compounds 2A-2D' were identified by $1 \mathrm{HNMR}$ (proton nuclear magnetic resonance) using amx-400 NMR, Mass using LC-MS 2010A and elemental analysis using Flash EA 1112 series Thermo Finnigan. TLC was performed using Solvent system- Ethyl acetate: n-Hexane, Stationary phase- Silica Gel-G.
Synthesis of Diethyl-2, 6-dimethyl- 1, 4-dihydropyridine-3, 5-dicarbohydrazide (1A) and diethyl-4-(4-hydroxyphenyl)-2, 6- dimethyl-1, 4-dihydropyridine-3, 5- dicarboxylate' $\left(1 \mathrm{~A}^{\prime}\right)^{11,12}$<smiles>[R]C1([R])C(C(=O)OCC)=C(C)NC(C)=C1C(=O)OCC</smiles>

\section{A-1A}

Synthesis of 2, 6-dimethyl-N3, N5- diphenyl-1, 4dihydropyridine-3, 5- dicarbohydrazide (2A-2D' $)^{13}$

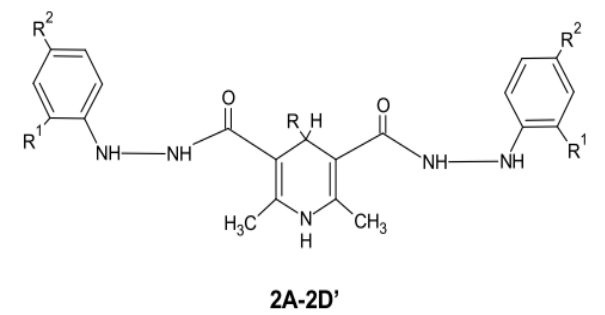

Substitutions for the derivatives are given in Table 1 .

\section{Pharmacological Activity}

Anti-inflammatory activity

\section{Carrageenan induced paw edema in rats}

Animals were weighed and numbered. A mark was made on the hind paw (left) just beyond tibio-tarsal junction, so that the paw was dipped in the mercury up to the fixed mark. Initial paw volume (left) was noted on each rat by mercury displacement method. Animals were divided into ten groups each comprising of six rats. The first group received dimethyl sulfoxide (vehicle), second group received intra 
peritoneal injection of indomethacin, third group to tenth group were treated with test compounds (2A-2D') intra peritoneally. After 30 minutes, $0.1 \mathrm{ml}$ of $1 \%(\mathrm{w} / \mathrm{v})$ carrageenan was injected in the plantar region of the left paw subcutaneously of all the groups followed by measurement of paw volume (left) of all the groups at $0,15,30,60$ and 120 minutes after carrageenan challenge. The increase in paw volume was observed and the percentage inhibition of edema exhibited by standard and test drugs was calculated by the following formula ${ }^{14,15}$.

$\%$ edema inhibition $=100$ [1-(Vt-Vo) Treated group $/(\mathrm{Vt}-\mathrm{Vo})$ Control $]$ $\mathrm{V} 0=$ Initial paw volume of the rat before the administration of carrageenan (at 0 minutes).

$\mathrm{Vt}=$ Final paw volume of the rat after the administration of carrageenan(at 120 minutes).

\section{Analgesic activity}

Analgesic activity was carried out by Eddy's hot plate method. Animals were divided into ten groups each comprising of six mice. The mice were treated with di-methyl sulfoxide (control), Tramadol (standard) and 2, 6-dimethyl$\mathrm{N}^{3}, \mathrm{~N}^{5}$-diphenyl-1, 4-dihydropyridine-3, 5-dicarbohydrazides (2A-2D') half an hour prior to analgesic screening. Eddy's hot plate method is used for screening of central analgesic property. The mice were placed on analgesiometer which is Eddy's hot plate kept and maintained at constant temperature $\left(55 \pm 1{ }^{\circ} \mathrm{C}\right)$. The time of response, that is the time taken by the animal to lick its hind paw or jump after placing it on the hot plate, is recorded as the reaction of painful stimuli. A cut off period of $15 \mathrm{sec}$ was considered to avoid the damage to the paw $^{14-16}$.

\section{RESULTS AND DISCUSSION}

The derivatives $1 \mathrm{~A}-1 \mathrm{~A}^{\prime}$ were synthesized using conventional Hantzsch method by condensation of ethyl acetoacetate with an aldehyde in the presence of ammonia and 2A-2D' were synthesized by condensation in the presence of respective phenyl hydrazines. Purity of these compounds was assessed using TLC and the structures were confirmed by ${ }^{1} \mathrm{HNMR}$, Mass, IR and Elemental analysis data. The newly synthesized derivatives 2A-2D' were screened for their in vivo antiinflammatory as well as analgesic activities by using carrageenan induced paw edema in rats and Eddy's hot plate method respectively. Among the derivatives screened, 2A, $2 \mathrm{C}$ and $2 \mathrm{D}$ exhibited good activity, $2 \mathrm{~B}^{\prime}$ and $2 \mathrm{C}^{\prime}$ has shown moderate activity, whereas other derivatives of the class namely 2B, 2A', and 2D' exhibited considerably low activity when compared with the standard indomethacin. Results summarized in Table 2 and Figure 1. All the derivatives which are screened for analgesic activity have shown significant activity in comparison with the standard tramadol. Derivatives 2A, 2B, 2A', 2C' has shown significantly good activity and the derivative $2 \mathrm{D}$ has shown moderate activity whereas the derivatives 2C, 2B', 2D' has shown lower activity when compared to other derivatives of the class as well as standard. The derivatives exhibited considerably good antiinflammatory and analgesic activities. Results summarized in Table 3 and Figure 2.

Table 1: Substitutions of the Synthesized Derivatives

\begin{tabular}{|c|c|c|c|}
\hline Compound & $\mathbf{R}^{\mathbf{1}}$ & $\mathbf{R}^{\mathbf{2}}$ & $\mathbf{R}$ \\
\hline $1 \mathrm{~A}$ & - & - & $\mathrm{H}$ \\
\hline $1 \mathrm{~A}^{\prime}$ & - & - & $\mathrm{C}_{6} \mathrm{H}_{4} \mathrm{OH}$ \\
\hline $2 \mathrm{~A}$ & $\mathrm{H}$ & $\mathrm{H}$ & $\mathrm{H}$ \\
\hline $2 \mathrm{~B}$ & $\mathrm{NO}_{2}$ & $\mathrm{NO}_{2}$ & $\mathrm{H}$ \\
\hline $2 \mathrm{C}$ & $\mathrm{H}$ & $\mathrm{Cl}$ & $\mathrm{H}$ \\
\hline $2 \mathrm{D}$ & $\mathrm{H}$ & $\mathrm{NO}_{2}$ & $\mathrm{H}$ \\
\hline $2 \mathrm{~A}^{\prime}$ & $\mathrm{H}$ & $\mathrm{H}$ & $\mathrm{C}_{6} \mathrm{H}_{4} \mathrm{OH}$ \\
\hline $2 \mathrm{~B}^{\prime}$ & $\mathrm{NO}^{2}$ & $\mathrm{NO}_{2}$ & $\mathrm{C}_{6} \mathrm{H}_{4} \mathrm{OH}$ \\
\hline $2 \mathrm{C}^{\prime}$ & $\mathrm{H}$ & $\mathrm{Cl}$ & $\mathrm{C}_{6} \mathrm{H}_{4} \mathrm{OH}$ \\
\hline $2 \mathrm{D}^{\prime}$ & $\mathrm{H}$ & $\mathrm{NO}_{2}$ & $\mathrm{C}_{6} \mathrm{H}_{4} \mathrm{OH}$ \\
\hline
\end{tabular}

Table 2: Anti-inflammatory Activity using Carrageenan induced Paw edema in Rats

\begin{tabular}{|c|c|c|c|c|}
\hline \multicolumn{5}{|c|}{ Carrageenan induced rat paw edema } \\
\hline Samples & Volume $\left(V_{0}\right)$ & $\begin{array}{c}\text { Maximum } \\
\text { Displacement }\left(V_{t}\right)\end{array}$ & $\begin{array}{l}\text { Percentage increase } \\
\text { in paw volume }(\%)\end{array}$ & $\begin{array}{c}\text { Percentage inhibition } \\
\text { of edema }(\%)\end{array}$ \\
\hline Control & $0.4272 \pm 0.0004$ & $0.7034 \pm 0.00128$ & 62 & - \\
\hline Standard & $0.3793 \pm 0.0003$ & $0.4511 \pm 0.00018$ & $19^{* * * *}$ & 74 \\
\hline $2 \mathrm{~A}$ & $0.4022 \pm 0.0002$ & $0.6106 \pm 0.0002$ & $52^{* * *}$ & 24 \\
\hline $2 \mathrm{~B}$ & $0.3894 \pm 0.00017$ & $0.6239 \pm 0.0002$ & $62^{* *}$ & 15 \\
\hline $2 \mathrm{C}$ & $0.3807 \pm 0.0002$ & $0.5884 \pm 0.00018$ & $54^{* * *}$ & 25 \\
\hline $2 \mathrm{D}$ & $0.3906 \pm 0.00025$ & $0.5819 \pm 0.00015$ & $49^{* * *}$ & 31 \\
\hline $2 \mathrm{~A}^{\prime}$ & $0.3676 \pm 0.00016$ & $0.6013 \pm 0.00016$ & $64^{*}$ & 15 \\
\hline $2 \mathrm{~B}^{\prime}$ & $0.3847 \pm 0.00016$ & $0.6167 \pm 0.00014$ & $61^{* *}$ & 16 \\
\hline $2 \mathrm{C}^{\prime}$ & $0.4361 \pm 0.00019$ & $0.6607 \pm 0.0002$ & $51^{* * * *}$ & 19 \\
\hline 2D' & $0.3744 \pm 0.00015$ & $0.6122 \pm 0.00022$ & $65^{*}$ & 14 \\
\hline
\end{tabular}

All values are expressed as mean $\pm \operatorname{SEM}(\mathrm{n}=6) .{ }^{*} \mathrm{P}<0.05,{ }^{* *} \mathrm{P}<0.01, * * * \mathrm{P}<0.0001$ significant compared to control

Table 3: Analgesic Activity using Eddy's hot plate Method

\begin{tabular}{|c|c|c|}
\hline \multicolumn{3}{|c|}{ Eddy's hot plate method } \\
\hline S. No & Sample & Response time (sec) \\
\hline 1 & Control & $3.17 \pm 0.4172$ \\
\hline 2 & Standard & $14.05 \pm 0.4517^{* * *}$ \\
\hline 3 & $2 \mathrm{~A}$ & $13.31 \pm 0.5103^{* * *}$ \\
\hline 4 & 2B & $13.07 \pm 0.6015^{* * *}$ \\
\hline 5 & 2C & $12.43 \pm 0.5819^{* *}$ \\
\hline 6 & 2D & $12.98 \pm 0.4197^{* *}$ \\
\hline 7 & $2 A^{\prime}$ & $13.52 \pm 0.7123^{* * *}$ \\
\hline 8 & 2B' & $12.15 \pm 0.5411^{* *}$ \\
\hline 9 & 2C' & $13.55 \pm 0.6121^{* * *}$ \\
\hline 10 & 2D' & $12.57 \pm 0.7012^{* * *}$ \\
\hline
\end{tabular}

All values are expressed as mean \pm SEM $(\mathrm{n}=6) .{ }^{*} \mathrm{P}<0.05,{ }^{* * *} \mathrm{P}<0.01,{ }^{* * *} \mathrm{P}<0.0001$ significant compared to control 


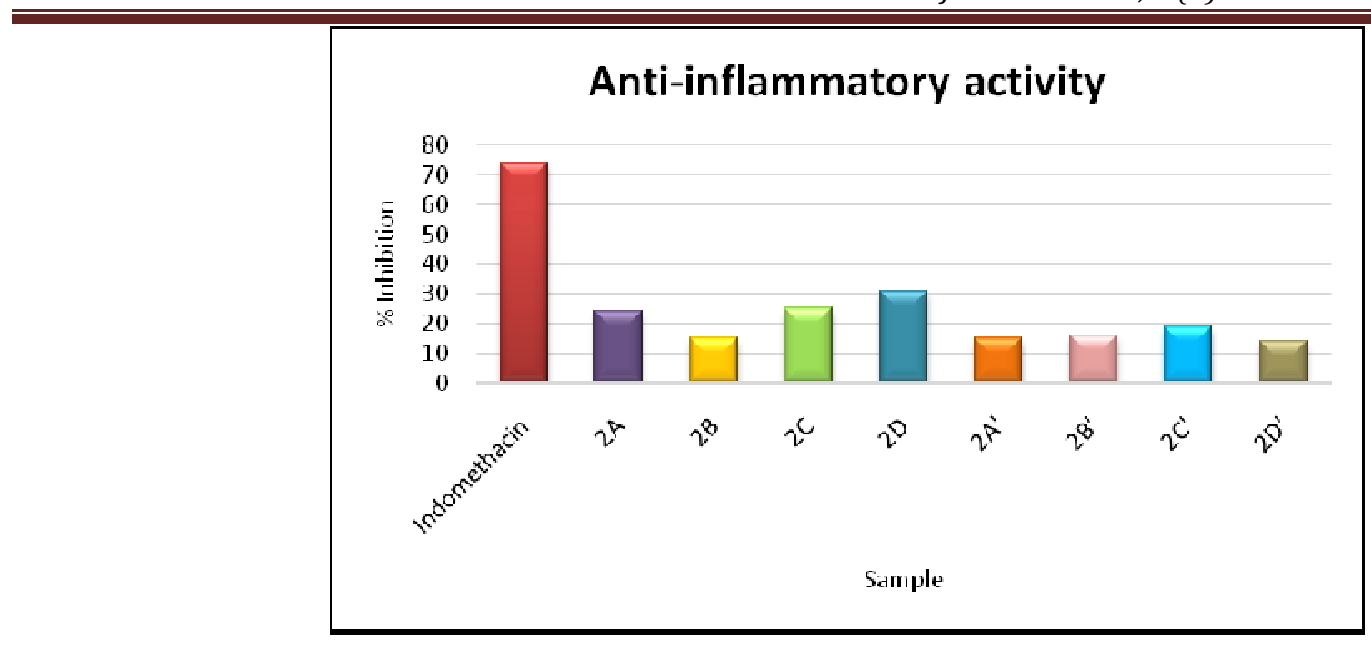

Figure 1: Anti-inflammatory Activity using Carrageenan induced Paw edema in Rats

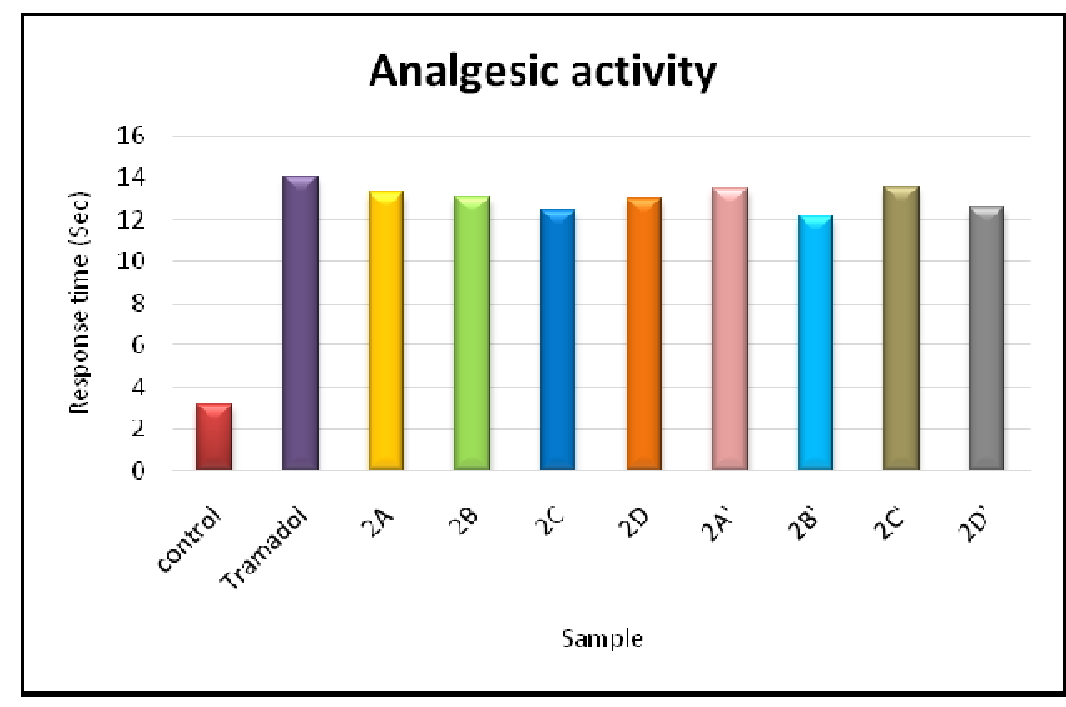

Figure 2: Analgesic Activity using Eddy's hot plate Method

\section{Statistical Analysis}

The experimental data were expressed as mean \pm SEM. The data were analyzed using ANOVA and Tukey-Kramer multiple comparison test. The results were considered statistically significant if $\mathrm{P}<0.05$.

\section{CONCLUSION}

These derivatives were synthesized with a rationale of developing lead molecules with better therapeutic efficacy. All the derivatives 2A-2D' have shown considerably good anti-inflammatory and analgesic activities. Analgesic activity is more when compared to the anti-inflammatory activity. Further study on these derivatives might provide a better insight into their pharmacological activities.

\section{ACKNOWLEDGEMENT}

I am grateful to express my sincere thanks to the Gokula Education Foundation (GEF medical), the Management and staff of M. S. Ramaiah College of Pharmacy, Bangalore, India for providing all the facilities and encouragement for carrying out the work. I am also thankful to Indian Institute of Science (IISC), Bangalore, India for their analytical services (Spectral data). I sincerely thank Mr. Riazuddin Mohammed, Department of Medical biology, Linköping University, Linköping, Sweden for animal studies.

\section{REFERENCES}

1. Beale JM Jr. Wilson and Gisvold's textbook of organic and pharmaceutical chemistry. $11^{\text {th }}$ ed. A Wolters Kluwer Company (NY): Lippincott Williams and Wilkins; 2004. p. 753-763.

2. Anil CK, Arya P, Chandrani M, Pankaj K, Yogesh Y and Ajendra SK. Microwave assisted synthesis of antimicrobial dihydropyridines and tetrahydropyrimidin-2-ones: Novel compounds against aspergillosis. Bio org and Med Chem 2006; 14: 973-981. http://dx.doi.org/10.1016 /j.bmc.2005.09.014 PMid:16214352

3. Rakesh K, Sakshi M and Ramesh C. Synthesis and antimicrobial activity of 4-[5-chloro-3-methyl-1-phenyl-1H- pyrazol-4-yl]-dihydropyridines and 4- [5-chloro-3-methyl-1-phenyl-1H- pyrazol-4-yl]-3, 4dihydropyrimidin-2- ones. Indian J Chem 2009; 48(B): 718- 724.

4. VL Gein, MI Kazantsera, AA Kurbatova and EV Voronina. Synthesis and antimicrobial activity of 2, 6-dimethyl-3, 5-dialkoxycarbonyl-4phenyl- 1, 4-dihydropyridines. Pharmaceutical chemistry Journal 2011; 45(8): 474-475. http://dx.doi.org/10.1007/s11094-011-0659-y

5. Tale Rajesh H, Rodge Atish H, Hatnapure Girish D, Keche Ashish P, Patil Kalpana $M$ and PawarRajendra P. The synthesis, anti inflammatory and anti-microbial activity evaluation of new series of 4(3-arylureido) phenyl-1, 4-dihydropyridine urea derivatives. Medicinal Chemistry Research 2013; 22(3): 1450-1455. http://dx.doi.org/10.1007/ s00044-012-0109-8

6. Bansal Ranju, Narang Gaurav, Calle Carmen, Rosalia Carron, Karen Pemberton and Alan L Harvey. Synthesis of 4-(Carbonyloxyphenyl)-1, 4-Dihydropyridines as Potential antihypertensive agents. Drug Development Research 2013; 74(1): 50-61. http://dx.doi.org/10.1002/ ddr. 21056

7. Pattan SR, Bhat AR, Taranill AD, Purohit SS and Reddy VVK. Synthesis of new 1, 4-dihydropyridine derivatives as antihypertensive agents. Indian J Heterocyclic Chem 2005; 15: 65-66. 
8. R Surendra Kumar, A Idhayadhulla, A Jamal Abdul Nasser, S Kavimani and S Indumathy. Synthesis and Anticonvulsant Activity of a new Series of 1, 4-Dihydropyridine Derivatives. Indian J Pharm Sci 2010; 72(6): 719-725. http://dx.doi.org/10.4103/0250-474X.84580 PMid:21969743 PMCid:PMC3178972

9. Shashikant PR, Purohit SS, Rasal VP, Mallya S, Marihal SC and Khade AB. Synthesis and pharmacological screening of some 1,4dihydropyridine and their derivatives for anticonvulsant activity. Indian J Chem 2008; 47(B): 626-629.

10. Ashraf AH, Ibrahim TM, Khaled AM, Lehmann J, Tinsley HN and Gary BD. Design, synthesis and biological evaluation of novel pyridine derivatives as anticancer agents and phosphodiesterase 3 inhibitors. Bio org and med chem 2009; 17: 5974-5982. http://dx.doi.org/10.1016 /j.bmc.2009.06.063 PMid:19628397

11. Raghavendra SR and Krishna NS. Superoxide induced oxidative aromatization of Hantzsch 1, 4- dihydropyridines. Indian J Chem 2008; 47(B): 1735-1738.

12. Elisa F, Angelo A and Mariella M. Photochemistry of Hantzsch 1, 4dihydropyridines and pyridines. Tetrahedron 2008; 64: 3190-3196. http://dx.doi.org/10.1016/j.tet.2008.01.104

13. Asma Samaunnisa A, Venkataramana CHS and Madhavan V. Synthesis, characterization and biological evaluation of novel $\mathrm{N}^{3}, \mathrm{~N}^{5}$ - diphenyl-1,4-dihydropyridine-3,5-dicarbohydrazide

derivatives. International Journal of Research in Pharmacy and Chemistry 2013; 3(1): 160-167.

14. Gerhard Vogel H. Drug discovery and evaluation, pharmacological assays. $2^{\text {nd }}$ ed. Springer; 2006. p. 696. http://dx.doi.org/10.1007/3-54029804-5

15. Fahmy HH and Soliman GA. Synthesis of new salicylamide derivatives with evaluation of their anti-inflammatory, analgesic and antipyretic activities. Archibes of Pharmacal Research 2001; 24(3): 180-189. http://dx.doi.org/10.1007/BF02978253

16. Asati KC, Srivastava SK and Srivastava SD. Synthesis of 5-arylidene-2aryl-3-(benzotriazloacetamidyl)-1,3-thiazololidin-4- ones as analgesic and antimicrobial agents. Indian Journal of Chemistry 2006; 45(B): 526531.

\section{Cite this article as:}

Asma Samaunnisa A, Riazuddin Mohammed, C.H.S. Venkataramana, V Madhavan. Evaluation of- 2, 6-dimethyl n3, n5- diphenyl - 1, 4dihydropyridine - 3, 5- dicarbohydrazide derivatives for in vivo antiinflammatory and analgesic activities. Int. Res. J. Pharm. 2013; 4(9):156-159 http://dx.doi.org/10.7897/2230-8407.04933 